\title{
MYOCARDIAL AND PERICARDIAL LESIONS DUE TO NON-PENETRATING INJURY
}

\author{
BY \\ ERIK WARBURG * \\ From the Section B of Internal Medicine, Rigshospitalet, Copenhagen \\ Received February 4, 1940
}

Subacute and chronic affections of the myocardium due to non-penetrating injuries have in the past been regarded as extremely rare. Traumatic rupture of the cardiac valves, papillary muscles, and chordæ tendinæ are described in detail in most textbooks; yet isolated myocardial and pericardial lesions, though undoubtedly more common, are scarcely mentioned except in more recent manuals dealing with diseases due to trauma, such as those by Stern (1930), Brady and Kahn (1937), and Spicer (1939). Papers by Beck (1935) and by Bright and Beck (1935) have dealt especially with such cardiac muscle injuries.

In my monograph (Warburg, 1938) I analysed 189 collected cases of traumatic heart disease, 158 of which seemed well substantiated, and added 13 new cases. This covered the long period from 1676, when Oluff Borch observed the first case, to the end of 1937. To these 202 cases analysed in 1938, I can now add 54 published cases previously overlooked and 5 new unpublished cases, making 261 in all. After excluding some of the earlier ones as doubtful, there remain 225 well-substantiated cases to form the basis of this review. One third of these have been published during the last five years.

The 59 new cases, not included in my previous study, are as follows: Bricheteau (1844), Steiger (1864), Müller (1879), Barth and Roger (1880), Reynier (1880) two cases, Barber (1912), Fraenkel (1917), Krumbhaar and Crowell (1925), Coffen (1930), Meixner (1931) four cases, E. E. Davis (1931), N. S. Davis (1931) two cases, Jervell (1933), Gunewardene (1934), Hawkes (1935), Kampmann (1935), Schilder (1935), Bean (1937) three cases, Kissane (1937) nine cases, Barber (1938) ten cases, Kienle (1938), Moritz and Atkins (1938), Peters (1938) two cases, Störmer (1938), Campbell (1939), O'Farrell (1939), Smith and McKeown (1939), Rajasingham (1939), Wüllenweber (1939), and five unpublished cases observed by or communicated to me.

\section{Pericarditis}

Blunt injuries to the heart must often cause pericardial hæmorrhage or fibrinous exudation. In the previous material of 202 cases, involvement of the

* Dr. Warburg had agreed that his paper should be considerably reduced to make it suitable for publication in this Journal. We are greatly indebted to Evan Bedford for compressing so much of the substance into much shorter compass. 
pericardium was mentioned in at least 50 , and in the new material in 10 cases, but I believe that pericardial lesions are actually far more frequent than is indicated by these figures. The diagnosis usually rests on pericardial friction sounds, but sometimes characteristic splashing sounds have been heard (bruit de moulin, bruit de rou hydraulique), indicating pneumopericardium; four such cases were found in my first series and I have since discovered six more, summarized below.

(1) Bricheteau (1844).-A shoemaker, aged 59, was hit in the chest by a waggon shaft, after which he suffered from pain in the chest for some years. His wife could hear a gurgling sound in his chest. He was admitted to hospital with cardiac failure ; tympany over the præcordium and a bruit de moulin were observed. He died within a few days and post-mortem showed fibrinous deposit over the pericardium, which contained 250 c.c. of sero-purulent fluid and much air.

(2) Steiger (1864).-A rural worker, aged 35, fell down 26 steps and hurt the left side of his chest against the frozen ground, causing a fracture of the left radius and injury to the left shoulder. Severe pain and dyspnœa followed, and two hours after the accident a splashing sound or bruit de moulin was audible at a distance from the chest. In the horizontal posture the cardiac dulness had disappeared. His ribs may have been fractured, but there was no hæmoptysis and no evidence of pneumothorax. After some days the splashing sound disappeared and pericardial friction developed. The patient recovered completely.

(3) Müller (1879).-A stone-cutter, aged 28, was crushed between two large stone flags, fracturing both clavicles and the left fifth and sixth ribs. He became breathless, the pulse accelerated, subcutaneous emphysema of the left chest wall appeared, and pericardial and pleural friction sounds were heard. Soon the cardiac dulness disappeared and the bruit de moulin was audible, ceasing in three weeks' time, when pericardial friction reappeared. After a period of fever the patient recovered completely, and left hospital ten weeks after the accident.

(4) Barth and Roger (1880).-A man, who three months previously had a fainting fit, fell down 12 metres and fractured both his arms. Tympanitic percussion note was found over the heart and a definite bruit de moulin; five months after the accident he had recovered.

(5) Reynier (1880).-A man fell down 5 metres and lost consciousness. He hurt his left side and felt severe pain in his left flank, where subcutaneous emphysema was found, reaching the præcordium. The fourth, fifth, and sixth left ribs were fractured. The bruit de moulin was heard with the patient lying, but disappeared when he sat up ; it lasted only 24 hours. No signs of pneumothorax. The patient seems to have recovered completely.

(6) Reynier (1880).-A man, aged 23, was crushed between the buffers of two railway carriages. He did not lose consciousness, there was no hæmoptysis, and shock was slight. He seemed to have fractured his fifth, sixth, and seventh left ribs. The bruit de moulin was heard and the cardiac dulness disappeared. One month afterwards he was discharged apparently cured.

Meixner (1931) has recorded a case of traumatic pericarditis with effusion in which 300 c.c. of clear fluid were aspirated, and Rajasingham (1939) another case in which 175 c.c. of hæmorrhagic pericardial fluid were removed ; both patients recovered. Paracentesis of the pericardium has, however, seldom been necessary, and in my previous paper there was only one case (Moullin, 1897) in which a large amount of fluid was removed by pericardiotomy. Characteristic cardiographic changes in a case of traumatic pericarditis have also been described (Smith and McKeown, 1939). 
The prognosis in traumatic pericardial lesions that are not complicated by extensive myocardial damage or by infection is benign. I have only found four fatal cases in which myocardial lesions were not present post-mortem, and these were described so briefly that myocardial damage cannot quite be excluded. Three or four cases developed pyogenic pericarditis and in several the injury was followed by tuberculous pericarditis. Finally, intrapericardial adhesions have been observed and in one case a constriction syndrome developed (Warburg, 1933).

\section{Auriculo-Ventricular Block}

My previous paper included 6 published cases of A-V block; in 3 the block was transient (Howat, 1920; Rosenson, 1924; Touhy and Boman, 1931) and in 3 it was permanent (Laubry, Bloch, and Meyer, 1921; Gallavardin, 1922; Warburg, 1928). Four additional cases are summarized below.

(1) Kampmann (1935).-A chauffeur, aged 43, was cranking his car when it backfired and caused him to fall down. He felt a stinging sensation in his chest and shortly afterwards collapsed with severe chest pain. Vomiting and attacks of unconsciousness followed and he was admitted to hospital, where the heart rate was found to be 32-36. He recovered, but several Adams-Stokes attacks occurred later, the last one 22 months after the accident. A cardiogram taken over two years after the accident showed slight prolongation of the $P-R$ interval.

(2) Kissane (1937). - A man, aged 35, passed as healthy at examination for life insurance nine months previously, was struck in the back by a slab of slating and doubled up. He felt a violent pain in his chest and was breathless. One month later the pulse was observed to be irregular, and he began to suffer from fainting fits. Six months after the accident examination showed enlargement of the heart and a systolic murmur. A cardiogram showed partial A-V block. He died nine months after the accident in a syncopal attack.

(3) Coffen (1930).-A healthy boy, aged 3, fell four feet, hitting his chest; no external injuries were noted. Next morning the heart rate was 65 and later in the day 50 . The rate fell to 36 in the following few days. At the age of 10, complete heart block was recorded by cardiogram. There was a pulmonary systolic murmur and X-ray showed a prominence due to the left auricle.

(4) Schilder (1935).-A man, aged 66, giving a history of being kicked on the chest in childhood, had been subject to paroxysmal tachycardia for five years. Examination showed signs suggesting arteriosclerotic aortic stenosis and incompetence, hypertension, and cardiac enlargement. Aged 66, he was struck by a waggon shaft on the lower part of the sternum, following which he collapsed and remained unconscious for three-quarters of an hour. Bradycardia, rate 35, was noted within 15 minutes of the accident, and two days later $2: 1$ block was recorded. Frequent Adams-Stokes fits followed, in one of which he died, four months after the accident. Autopsy showed considerable hypertrophy of the heart and myocardial fibrosis. The coronary arteries were stenosed and calcified, but the valves were normal.

The prognosis in traumatic heart block is not always bad. Of the ten cases cited, four died while under observation; one lived 6 weeks, one 4 months, one 9 months, and one 13 years. The remaining cases were alive and under observation for periods of $1,11 / 2,41 / 2$, and 5 years respectively; one, only observed for 3 months, was quite well. Heart block of undetermined ætiology is by no means rarely seen, especially in young subjects, and in some of these cases it may be due to trauma. In three of the cited cases with permanent 
heart block due to trauma, the age at the time of injury was 3,16 , and 21 years respectively.

Sino-auricular Block.-Kissane (1937) has described a case of contusion of the heart in a soldier who was struck on the chest by a bayonet, near the apex beat. He became breathless and felt pain in the left chest and shoulder; a systolic murmur appeared at the apex. Eighteen years later a cardiogram showed sino-auricular block.

\section{Changes in the Ventricular Complex of the Cardiogram}

The best evidence that injury has caused a myocardial lesion is a changed ventricular complex appearing immediately after the trauma. Usually the changes observed have been regressive, but occasionally progressive changes have been recorded.

My previous paper included 12 cases of injury that caused cardiographic changes such as heart block, auricular fibrillation, and flutter, and also QRS and T changes. My new material includes 8 further cases as follows : Kissane (1937), curves of posterior infarction; Kienle (1938), $T$ wave changes of posterior infarction and nodal rhythm; Störmer (1938), T wave changes of posterior infarction; Smith and McKeown (1939), R-T elevation followed by T inversion associated with pericarditis; Kissane (1937), R-T elevation in lead III followed by low voltage curves; Meixner (1931), T inversion and slurring of QRS, followed by auricular fibrillation; Campbell (1939), low voltage $T_{2}$ and inversion of $\mathrm{T}_{3}$; lastly my own case, summarized below.

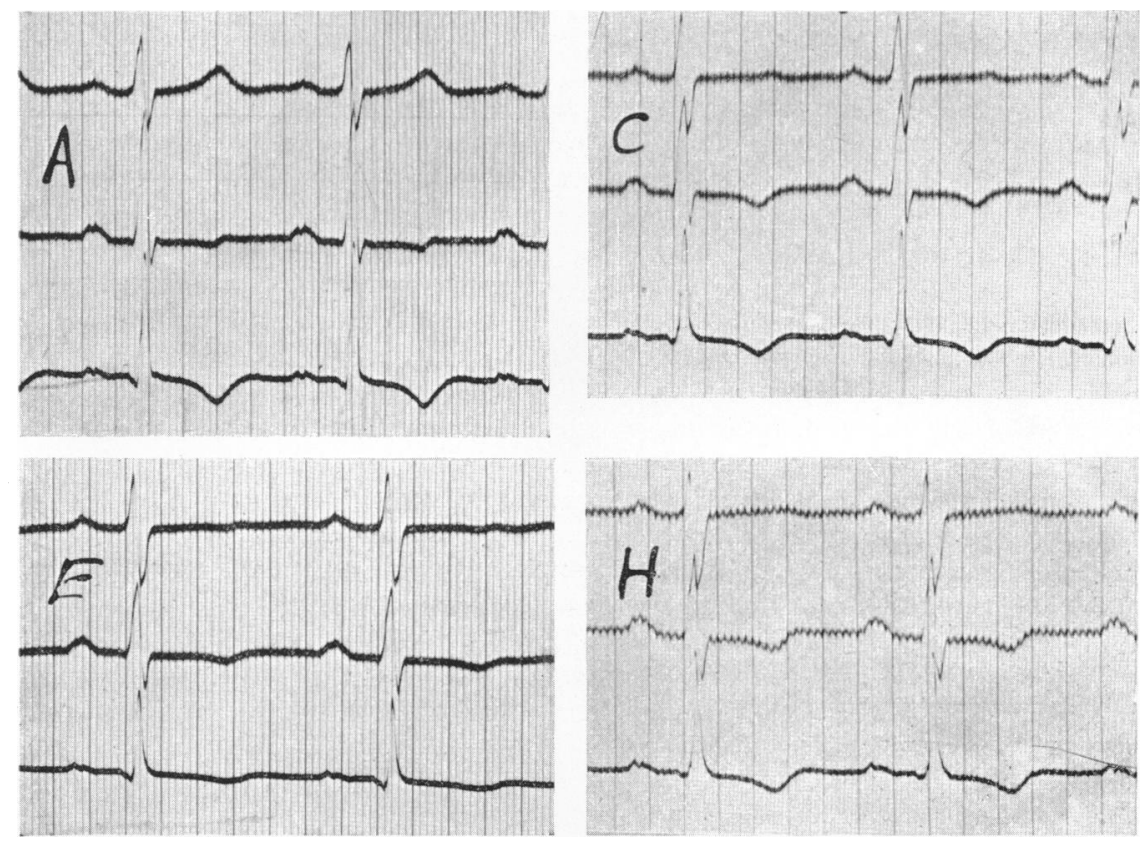

FIG. 1.-Serial cardiograms from case of myocardial trauma five months after the accident (A) April 13: (C) April 30 ; (E) May 16; (H) June 9, 1938 (leads I, II, and III from above downwards in each cardiogram). 
Warburg (1938) (case communicated by Dr. Voght-Moller).-The patient had enjoyed good health up to November 1937, when he slipped and fell while loading turnips into a cart ; he felt pain in the chest radiating to the right arm, became breathless, sweated, and lay on the ground for five minutes. He was unable to work for some days, and after a temporary improvement became more breathless. Five months after the accident he was admitted to hospital suffering from violent attacks of pain in the chest combined with tachycardia, rate 160. Systolic and diastolic aortic murmurs were audible, with the Wassermann reaction negative. He died of cardiac failure eight months after the accident. During his stay in hospital, seven cardiograms were obtained, four shown in Fig. 1. The later curves show inversion of $\mathrm{T}$ in leads II and III and an isoelectric T in lead I.

Autopsy.-Heart weight, 270 g. No pericarditis. Right auricle distended; left auricle normal. Valves normal. Ventricles normal. Just below the aortic valves a minute yellowish thickening of the endocardium of the left ventricle. Coronary arteries normal. Section of the heart showed a thin area on the lower posterior wall of the right auricle to which a few small thrombi were adherent, and the auricular appendix also contained thrombi. Sections of the ventricular and septal muscle showed no appreciable abnormality.

Thus at least 23 cases with transitory changes in the cardiogram following injury have been reported; 2 of these are known to have died after nine months and five years respectively. In 14 cases the period of observation varied from a few weeks up to seven years. In 8 cases recovery was stated to be complete. Thus the prognosis in the milder cases is good, especially if the patient is not too old and has not had previous cardiac symptoms.

\section{Auricular Fibrillation}

Auricular fibrillation is not rare in traumatic myocardial lesions, and my previous review included 41 cases of established and 4 of transitory fibrillation or flutter. The new material includes 10 cases of complete irregularity, i.e. one fifth of all cases, as in my previous series.

The new cases are summarized below.

(1) Jervell (1933).-An athlete, healthy when examined previously, was knocked down by a car, which struck the back of his chest. Shortly afterwards the pulse became rapid and irregular; a cardiogram, nine months later, showed auricular fibrillation. Normal rhythm was restored by quinidine and the patient remained well during two years' observation.

(2) Bramwell (1934).-A mason, aged 35, previously healthy, struck his head against a beam ; he vomited and had severe headache for some days. Nine days after the accident auricular fibrillation was found, without cardiac enlargement or signs of failure. Neurological examination was negative. Normal rhythm was restored by quinidine and he was well a year later.

(3) Barber (1938). - A healthy man, aged 58, was hit on the head by a signboard and entered hospital with an injury of the cervical spine. His pulse, at first 80-90, accelerated to 120 after ten days, and a cardiogram three months later showed auricular flutter. Heart enlarged : B.P. $160 / 100 \mathrm{~mm}$.

(4) Barber (1938).-A man, aged 61, was admitted to hospital after being run down by a car, and a few days later his pulse became irregular. His capacity for work diminished, and eleven months later a cardiogram showed fibrillation, apart from which the heart was normal. Five years later there was no change.

(5) Barber (1938). - A man, aged 63, was run down by a car, and on admission to 
hospital a cardiac irregularity was noted. On leaving hospital he was breathless, and six weeks after the accident a cardiogram showed auricular fibrillation; otherwise the heart was normal.

(6) Kissane (1937).-A man, aged 45, previously healthy, was hit on the back by a slab of slate and fell against a waggon, fracturing the second and third left ribs. Dyspnœa, pain in the chest, and hæmoptysis followed, and auricular fibrillation developed. Two years later there was cardiac enlargement and failure. A cardiogram showed fibrillation. Six years after the accident he was worse.

(7) Kissane (1937).-A man, aged 55, previously healthy, was struck on the sternum in a motor accident, and on admission to hospital the heart was irregular. He suffered from dyspnœa and sternal pain on effort, and, six months later, had a cerebral embolism. Nine months after the accident there was auricular fibrillation, cardiac enlargement, and signs of failure.

(8) Moritz and Atkins (1938).-A man, aged 74, was run down by a car, sustaining extensive injuries including fractures of two ribs. Auricular fibrillation developed the next day, and he died of heart failure ten days afterwards. Necropsy showed fibrinous pericarditis, hæmorrhages into the right auricle, extensive coronary sclerosis without recent thrombosis, and hæmorrhagic necrosis in an old infarcation of the right ventricle, regarded as of traumatic origin.

(9) O'Farrell (1939).-A man, aged 59, experienced severe pain in the left chest and dyspnœa, after a motor accident. There was fracture of a left lower rib. Three weeks later he had an attack of dyspnœa and auricular fibrillation was found. He died of heart failure three months after the accident. Necropsy showed a left pleural effuision, pericardial thickening, and adhesions at the apex, covering a cardiac aneurysm and myocardial fibrosis. Slight sclerosis of mitral and aortic valves. No coronary occlusion.

Thus of 10 cases of fibrillation, 2 recovered completely, 2 died ten days and three months after the accident respectively, and the remaining 6 showed signs of cardiac impairment.

\section{EXTRASYSTOLES}

Extrasystoles following trauma have seldom been reported. My original paper included 9 cases and there are only 2 additional ones. Barber's patient, a syphilitic, was injured by a bull, fracturing three ribs, after which the pulse was irregular from frequent extrasystoles, and remained so a year later. Meixner's patient, besides extrasystoles, had $T$ wave abnormalities in the cardiogram.

\section{Angina Pectoris}

The possibility of angina pectoris being caused by trauma was first discussed by Hans Kohn (1929), who collected 4 cases; 2 of these seem doubtful and 2 had syphilitic aortitis, making it difficult to decide the role of trauma in the pathogenesis of the anginal syndrome. I was able to collect 13 published cases and to add 6 cases of my own, but only two thirds of these 19 cases could be accepted as well-substantiated.

Excluding cases in which the history was inadequate or in which the interpretation of the anginal symptoms was doubtful, my new material includes 16 cases of angina pectoris following trauma, as follows: Kampmann (1935), 
Kissane (1937) 4 cases, Kienle (1938), Störmer (1938), Barber (1938) 4 cases, Peters (1938) 2 cases, Wüllenweber (1939), Dahle (1939), and Warburg (1938).

These cases were mostly men over 40 years of age, who had been in good health prior to accidents that often involved injury to the chest, and developed anginal pain shortly afterwards. The following two cases may be cited as examples.

(1) Peters (1938).-A man, aged 54, free from cardiac symptoms, was involved in a car accident, fracturing his right arm. He was in severe pain for two days, and a week later developed oppression in the left chest and arm. There were no abnormal signs in the heart and the blood pressure was normal. He died during a severe anginal attack a fortnight after the accident. Necropsy: coronary sclerosis without occlusion; mild fibrosis and fatty infiltration of the myocardium. An insurance company refused to accept the accident as the cause of death.

(2) Warburg (1938).-A man, aged 62, previously healthy except for glycosuria, had a cycle accident in 1935 which caused a swelling in one rib. In April 1937 he was run over by a car. He continued his work with difficulty for a week, after which he developed severe pain in the chest and stayed in bed for two days. On attempting to return to work he again had violent mid-sternal pain extending to both arms, and had to return to bed. After this he was unable to work until January 1938 . In August 1938 he was subject to typical angina of effort, but was able to do light work. Examination showed the pulse regular, rate 48 . Blood pressure, $180 / 80 \mathrm{~mm}$. No signs of heart failure. X-ray and cardiogram showed no abnormality.

In most cases the pathogenesis of the anginal pain is probably explained by a vascular lesion ; but Peters suggested that peripheral stimulation from a broken arm caused coronary spasm, and Wüllenweber suggested interference with the coronary vasodilator fibres in a case with injury to the spinal cord.

My previous study included 2 cases of coronary thrombosis and 1 case of injury to a coronary branch following accidents, and I know of 6 other cases of traumatic coronary occlusion. The following may be cited as examples.

Fraenkel (1917).-A soldier, aged 20, was wounded by a shell explosion which caused an injury to his right arm and also concussion. He died six months later with cardiac failure. Necropsy showed an aneurysm of the left ventricle due to an aneurysmal dilatation of the left descending coronary artery, which was blocked by thrombi. The lesion was attributed to general concussion due to the shell injury.

Muller (personal communication).-A barrister, aged 59, free from cardiac symptoms, was run over by a bicycle, falling on to his thorax and abdomen. He sustained no external injuries and was able to get up immediately and walk to his office. He continued his work during the following days, though he did not feel well and experienced substernal oppression when walking upstairs or uphill. Nine days after the accident he had a severe nocturnal anginal attack and was admitted to hospital. The clinical picture became typical of cardiac infarction ; there was fever, leucocytosis, and typical R-T changes in the cardiogram. He died two weeks after the accident, with cardiac failure. Necropsy showed thrombotic occlusion of the left descending coronary artery with a large cardiac infarct and recent pericarditis. There was arteriosclerosis of the occluded branch and to a lesser degree of other branches. 


\section{Non-Penetrating Cardiac InJuries in Children}

Hawkes (1935) reported the following case of cardiac aneurysm. A boy, six years old, was hit by a truck. The diagnosis was compression of the chest and multiple abrasions of the body. He was discharged after one week as cured. He continued his usual life at home until three months after the accident, when he came home from school feeling sick. While eating his supper he fell off his chair, dead. At autopsy a ruptured traumatic aneurysm of the left ventricle with hæmopericardium was found. The aneurysm was globular, thin-walled, and on the posterior surface of the ventricle. It measured $4 \mathrm{~cm}$. in diameter with a rupture at the summit, $0.5 \mathrm{~cm}$. in diameter. No rheumatic or syphilitic lesion was found. There was no chest wall injury or fracture.

Gunewardene (1924) has described the case of a boy, aged 9, who was crushed against a wall without receiving any obvious injuries. Ten days later he died suddenly while playing at school. Necropsy showed hæmopericardium from rupture of the left ventricle. Similar cases described by Groom (1897) and by O'Neill (1914) were cited in my original paper.

\section{Site AND TyPE OF INJURY}

In almost all cases in which the site of the injury has been stated, the thorax has been involved, usually by being struck from the front. In several cases the back was hurt, in one the right shoulder, in one the head, and two patients fell on their buttocks. Injuries distant from the heart may damage it, though very rarely. The accidents occurring in the present series of cases were similar in nature to those in the first series, and are tabulated below. Details were given in 57 of the 59 cases.

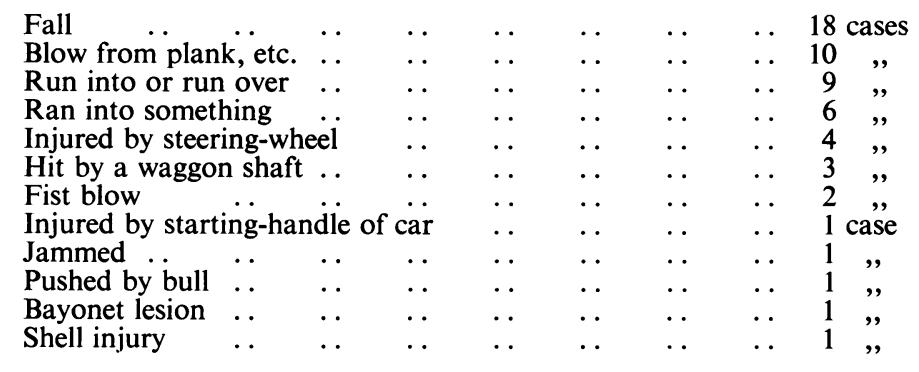

\section{DiAGNOSIS}

The diagnosis of traumatic myocardial disease depends on a careful history. Often the heart is not perfectly normal prior to the accident, and both arteriosclerosis and hypertension may be predisposing factors. This was so in 10 cases of my first series and in 14 cases of the new series. 'Meixner (1931) in discussing this question concluded that the coronary arteries were frequently affected in sudden exertion or in sudden falls, and that if there should happen to be a lesion making them susceptible to rupture, a coronary thrombosis might occur owing to rupture of the intima; or, on the other hand, an aneurysm of the 
ventricle might occur with subsequent rupture, or a pericarditis with subsequent rupture of the auricle. Difficulty may arise because, in some cases, the patient's condition immediately following the accident is not conspicuously bad. More often than not the patients do not faint, and in the present 59 cases fainting was specified in only 4 , while in 24 absence of fainting was explicitly stated. There may be a latent period of a few days up to several months between the accident and the appearance of cardiac symptoms, as happened in 10 of the present cases. Almost every known abnormality of the electrocardiogram has been observed, yet in many cases there was no abnormality.

\section{Prognosis}

It is impossible to generalize about prognosis. The present material includes cases that recovered within a few weeks, many that developed chronic heart failure, and others that died fairly soon after the injury. Of my previous series, 74 patients are known to have died from their traumatic cardiac lesion and in the present series 16 out of 59 cases ended fatally. The period of survival is known in 14 of these cases and was 7 days, 10 days, 10 days, 2 weeks, 3 months, 3 months, 4 months, 9 months, and 2 years respectively.

\section{SUMMARY}

Another 59 cases of myocardial or pericardial damage due to non-penetrating blunt injuries have been collected and are reviewed with data from a previous series of 202 similar cases.

The traumatic cardiac lesions described include pericarditis, heart block, myocardial damage, auricular fibrillation and other disturbances of rhythm, and angina pectoris. Auricular fibrillation occurred in a fifth and angina pectoris in a quarter of these 59 cases. Seven cases of traumatic coronary thrombosis are cited.

In almost all cases the injury involved the thorax, sometimes fracturing one or more ribs, but in a small proportion injuries distant from the heart were responsible for cardiac damage.

Arteriosclerosis and hypertension were sometimes present and may have rendered the heart more susceptible to injury from violence to the chest.

\section{REFERENCES}

Barber, H. (1912). Practitioner, 89, 230.

Barber, H. (1938. Brit. med. J., 1, 432.

Barth and Roger, H. (1880). Traité pratique d'Auscultation, $2^{e}$ edit., Paris, pp. 446 and 752.

Bean, W. B. (1937). Amer. Heart J., 14, 684.

Beck, C. S. (1935). J. Amer. med. Ass., 104, 109.

Borch, O. (1676). Acta medica et philosophica. Hafniensia IV. Obs. XLVII, p. 150.

Brady and Kahn, S. (1937). Trauma and Disease. Philad., pp. 24-78.

Bramwell, C. (1934). Lancet, $1,8$.

Bricheteau (1844). Arch. gén. Méd., 64, 334.

Bright, E. F., and Beck, C. S. (1935). Amer. Heart J., 10, 293.

Campbell, M. (1939). Brit. Heart J., 1, 177.

Coffen, H. (1930). Amer. Heart J., 5, 667. 
Davis, E. E. (1931). Illinois med. J., 60, 473.

Davis, N. S. (1931). Ibid., 60, 473.

Fraenkel (1917). Dtsch. med. Wschr., 13, 159.

Gallavardin, L. (1922). Lyon méd., 131, 545.

Groom, W. (1897). Lancet, 1, 1,202.

Gunewardene, H. O. (1934). Brit. med. J., 2, 942.

Hawkes, S. Z. (1935). Amer. J. Surg., 27, 503.

Howat, R. K. (1920). Lancet, 1, 1,313.

Jervell, A. (1933). Norsk. Mag. Laegevidensk., 94, 14.

Kampmann, W. (1935). Münch. med. Wschr., 82, 129.

Kienle, F. (1938). Z. Kriesl Forsch., 30, 674.

Kissane, W. (1937). Ohio State University Studies, Columbus, p. 87.

Kohn, H. (1929). Klin. Wschr., 8, 795 and 843.

Krumbhaar, E. B., and Crowell, C. (1925). Amer. J. med. Sci., 170, 828.

Laubry, C., Bloch, S., and Meyer, J. (1921). Bull. Mem. Soc. méd. Hop. Paris, $3^{e}$ ser., 45, 1,363 .

Meixner, F. M. H. (1931). Illinois med. J., 60, 469.

Moritz, A. R., and Atkins, J. P. (1938). Arch. Path., 25, 445.

Moullin, M. (1897). Lancet, 1, 314.

Müller, H. (1879). Dtsch. Arch. klin. Med., 24, 158.

O'Farrell, P. T. (1939). Brit. Heart J., 1, 172.

O'Neill, B. J. (1914). J. Amer. med. Ass., 9, 697.

Peters, J. T. (1938). Critical Views of the Standpoint of an Accident Insurance Company with regard to the Connection between Accident and Sudden Death by So-called Paralysis of the Heart. Guildford and Esher.

Rajasingham, A. S. (1939). Brit. Heart J., 1, 181.

Reynier, P. (1880). Arch. gén. Méd., $7^{e}$ sér., 5, 441.

- (1880). Thése de Paris, 1880.

Rosenson, W. (1924). Amer. J. Dis. Child., 24, 594.

Schilder, G. (1935). Med. Klinik, 31, 1,572.

Smith, L. B., and McKeown, H. J. (1939). Amer. Heart J., 17, 560.

Spicer, F. W. (1939). Trauma and Internal Disease. Philad., pp. 179-223.

Steiger, C. F. (1864). Würzburg. med. Z., 5, 124.

Stern, R. (1930). Traumatische Entstehung innerer Krankheiten. 3 Ausg., Jena., pp. 39-117.

Störmer, A. (1938). Dtsch. med. Wschr., 64, 235 and 260.

Touhy, E. L., and Boman, P. G. (1931). Ann. Int. Med., 4, 1,372.

Warburg, E. (1933). Nord. med. Tidskr., 6, 833.

(1938). Subacute and Chronic Pericardial and Myocardial Lesions due to Non-penetrating Traumatic Injuries. Copenhagen and London.

Wüllenweber, G. (1939). Z. KrieslForsch., 31, 16. 